\title{
Does Reliability Pay? How Reputation Can Affect Transaction Governance Investments
}

\author{
Alfred G. Warner, (E-mail: agw2@psu.edu), Penn State University, Erie \\ Peg Thoms, Penn State University, Erie \\ Janice A. Totleben, Penn State University, Erie
}

\begin{abstract}
The role of trust in economic exchange is ill-defined. Trust between alliance partners is argued to sometimes be an alternative to costly governance mechanisms and can therefore lead to superior performance. On the other hand, relying on anything but investments to secure credible commitment to deterrence is described as myopic. This paper explores a middle ground where, in the context of a reputation network, governance costs can decline without the strict necessity of intentional trust. Using an experimental approach, we show that reputation effects lead to significant advantages for reliable players in terms of offers to ally and the quality of those offers. These advantages resulted in lower governance costs and better performance
\end{abstract}

\section{INTRODUCTION}

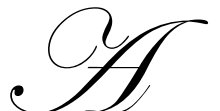

ccurately predicting how others will act in economic exchange would be a very valuable ability indeed. With it, economic actors could choose the right partners, avoid investment in costly governance mechanisms to prevent defection and loss, and increase their own returns. Trust is such a prediction: scholars investigating it argue that intentional trust develops between partners as a result of the familiarity that arises from repeated transactions (Gulati 1995a; Gulati and Singh 1998; Nooteboom et al. 1997) or because partners are aware that to act otherwise is counter to a organizational or personal values and standards (Barney and Hansen 1994). In these cases, exchange partners can deliberately elect not to invest in governance because they can reasonably rely on the other not to take advantage of that vulnerability. Exchanges between mutually trustworthy partners can lead to higher returns.

Conversely, Williamson (1993a, p 469) argues that "trust is irrelevant to economic exchange" because of the joint effects of bounded rationality and the threat of opportunistic behavior in others. Since we cannot absolutely determine, ex ante, the reliability of a potential partner, exchange conditions such as complexity, uncertainty or asset specificity warrant that we invest in governance to protect our positions. Our trust here is situational in that we do not rely on the other's good will but only in their economic self-interest because the cost of defection is too high. In this view, there is no opportunity to reduce the costs of governance.

In this paper, we explore a space between these perspectives. In the context of a series of exchanges which creates a reputation network, we argue that farsighted agents will recognize that reliable, cooperative behavior is in their own economic self-interest and can lead to superior performance. If an agent can be predicted to cooperate in an exchange, then partners can reduce their own costs of governance. Reliable actors should be preferred partners and therefore enjoy more exchange opportunities. Second, among this larger group of offers, reliable actors should also find higher quality offers, that is, more reliable potential partners and thereby be able to choose better partners. Ultimately, reliable firms should be able to conduct their own transactions with comparatively lower governance costs, leading to a performance advantage. 
This approach differs from the contrast between intentional and situational trust we drew above in the following ways. First, our notion of reliability in this paper is not as constraining as intentional or strong-form trust: we argue that self-interest is a sufficient bond. Put differently, actors do not have to have deep or strong trust in prospective partners, but only the belief that the other will act in her own interest. Second, the opportunity cost of lost or inferior future transactions will act as a sufficient governance mechanism. The value of reputation discourages defection (Kreps 1990a) and permits some actors to enter exchanges without the usual governance expenditures. We characterize the exchanges in our paper as alliances because the actors are autonomous and the transactions exhibit asset specificity, creating the risk of opportunistic behavior (Williamson 2002).

A fundamental problem in investigating propositions like these empirically is that the data are difficult to secure. Most empirical work in trust and alliances concerns alliances that have actually existed rather than with the possibilities of alliance (Gulati 1995a, 1995b; Gulati and Singh 1998; Parkhe 1993; Reuer and Arino 2002). Reuer and Arino (2002) do inquire into the pool of potential alliance partners a firm has but this is self-reported assessment by the focal firms and may not reflect the perspective of the potential partners. Moreover, determining the reputation of a firm is extremely difficult (de Castro et al. 2006; Deephouse 2000). Therefore, following Olk and Elvira (2001), Knez and Camerer (1994), and Dollinger, et al (1997), among many others, we developed an experimental study using MBA students to determine if the reputations players develop matter in terms of numbers and quality of offers, as well as the ultimate performance of those players.

\section{THEORY AND HYPOTHESES}

The objective of transaction analysis is to minimize the combined costs of opportunism and governance through discriminating alignment or the match of transaction and governance form (Williamson 1991). From a transaction cost economics (TCE) perspective, alliances are an intermediate form of governance, preserving market like incentives but also entailing bilateral dependency between parties. In market based transactions, clear and complete contracts ex ante and unambiguous contractual performance are the rule (Ring and Van de Ven 1992) and the identity of the partners is not important nor are the parties to the exchange dependent on the other. Transactions are comparatively well defined and subject to the constraints of contract law. Alliances differ from spot transactions in that while the parties remain independent, specific investments made to further the alliance create dependencies and are subject to compromise by partners because the contracts that define the alliance and the rights to the rents from those investments are more complex than spot contracts and incomplete. Exchange partners are bilaterally dependent to the extent they cannot easily or economically resort to a "next-best" use for the assets dedicated to the exchange (Williamson 2002) which generates the opportunity for gains through hierarchical control (Williamson 1991). Specifically, Williamson (1975) argues that when transactions are attended by uncertainty, recur frequently, and assets have been made specific to the transaction, hierarchical control is indicated.

Bounded rationality renders complex contracts incomplete and parties to the exchange can exploit contractual gaps through strategic or opportunistic behavior. Williamson argues opportunism "engages the realpolitiks of economic organization" (Williamson 1993b, p 98) because human actors are self-interested and "will not reliably...self-fulfill all promises. Contract as mere promise, unsupported by credible commitments, will not, therefore, be self-enforcing" (Williamson 1999, p 1089). Although some argue that TCE assumes all actors are opportunistic (e.g., Ring and Van de Ven, 1992), it is not necessary that parties to the exchange believe that the other will act opportunistically, only that uncertainty about the other's intentions makes the creation of governance in the presence of bilateral dependency prudent (Ghoshal and Moran 1996; Williamson 1993b). In consequence, private ordering or more hierarchical governance emerges when the parties are foresighted enough to recognize potential hazards and devise mechanisms to mitigate those hazards such as dispute settlement through bureaucracy, arbitration and information disclosure. Governance efficacy is thus determined both by private ordering and by the institutional mechanisms such as the laws of property and contract and the courts (Williamson 1991).

Under some conditions, trust between partners is argued to substitute for costlier forms of governance in alliances. Scholars distinguish between several forms of trust. There is first the expectation or reliance of performance that stems from well structured governance mechanisms (variously termed "calculative" (Williamson 1993a), "semistrong form" (Barney and Hansen 1994), "deterrence based" (Gulati 1995a), or "risk based" trust (Ring and Van de 
Ven 1994)). Here, parties to an exchange anticipate that partners will not default because the mechanisms in place make it costly to do so. That is, behavior is situationally motivated (McCabe et al. 2003). Because the reliability is a function of investments in governance, though, there is no opportunity to use trust to economize on transactions costs. A different type of trust (termed "intentional" (Nooteboom et al. 1997), "strong form" (Barney and Hansen 1994), "goodwill based" (Ring and Van de Ven 1994), or "behavioral" trust (Gulati 1995a)) is based on beliefs about intrinsic characteristics of the partner such as values and principles. In this case, trust emerges as an assessment of the intentional state of the other (McCabe et al. 2003).

An example of how intentional trust is argued to reduce transaction costs comes from work showing that direct (i.e., dyadic) trust is built as firms repeatedly interact (Gulati 1995a, 1995b; Gulati and Singh 1998). As the number of prior alliances increases, the likelihood of the governance of a subsequent alliance being equity based (with equity as the deterring investment) decreases. As the result of repeated experience or habitualization, the subjective assessment of the probability of loss decreases (Nooteboom et al. 1997). Parkhe (1993) also finds empirical support for the link between experience and a decrease in the perception of opportunistic behavior.

We argue that, absent other information, this argument reflects unwarrantedly optimistic posterior reasoning. Suppose that $A$ and $B$ have engaged a series of exchanges marked by at-risk rents and corresponding investments in governance mechanisms. A observes that $\mathrm{B}$ has behaved properly in all transactions and now considers how to govern the next exchange. If the repeated interactions argument is correct, A should be inclined to regard B as trustworthy and forego governance investments. However, A cannot determine if the reason B cooperated was because of the governance mechanisms or because B is inherently trustworthy: A has absolutely no new information about B's trustworthiness and the new governance decision is precisely the same as the decision faced in the first exchange. A might correctly believe that B is trustworthy but the history of transactions provides no evidence to support that belief. Thus, Williamson argues "that the study of economic organization is better served by treating commercial transactions without reference to trust" (Williamson 1993b, p 99). As a reflection of this, contra Gulati, recent empirical work suggests that even after repeated ties, firms elect to maintain governance investments if the asset specificity is high (Casciaro 2003; Reuer and Arino 2002).

Nonetheless, the idea of reducing the subjective assessment of opportunism is not extinguished. Although the threat of opportunism is often taken as given, Williamson observes that hazards of exchange vary with both the nature of the transaction and with the trading environment (Williamson 1993a). Specifically, Williamson regards the institutional environment as a set of shift parameters and as these change or differ, the comparative costs of the governance choices change. For example, social culture can inhibit or encourage opportunistic behavior through variations in structures such as courts or property law. At a more informal level, professionalism and networks can moderate the governance choices.

To illustrate, Williamson analyzes the way transactions are conducted on the diamond bourse in New York where binding agreements for diamond purchases are made on the basis of a handshake and uttering the phrase mazel u'broche (Bernstein 1992). Williamson disputes that the transactions are (intentionally) trust based. Rather, the informality is possible because the community of traders was able to develop sanctions internally that dealt with default or deceit. Traders in the Diamond Club agree to submit all disputes arising from trade to one of two dispute resolution bodies where resolution is based on trade custom and usage (often published in the Clubs bylaws). Punishments for default range from the financial to suspension or expulsion from the Club so the bourse acts as reputation signaling and monitoring mechanism (Bernstein 1992). Williamson argues that the establishment of these network based trading rules provides safeguards (sanctions) that reduce the need for transaction specific governance investments.

We extend this idea to argue that when reputation exists, reputation matters and the sanctions need not be imposed by communal act or collective agreement. Rather, in networks where information about reputation is available, sanction can emerge in a market-like way from the decisions of self-interested actors about with whom to transact and thereby generate the opportunity for reduced governance costs. More specifically, as parties develop reputations for how they conduct transactions, others will use those reputations to decide if and how to engage in 
exchange (Kreps 1990a). In this way it differs from the "absent other information" problem of exchange governance in direct trust situations.

Reputation is a belief or signal about the true type of a potential partner (Weigelt and Camerer 1988) that stems from observation of past actions and permits prediction of future action (Parkhe 1993). Economic actors can build a reputation for trustworthy behavior much as they can in the repeated ties framework: through consistent, cooperative performance in a context (such as a network) where such performance is noted. Similarly, actors can lose status through default on a transaction. Just as default on the diamond bourse becomes well known to the community and the transgressor's reputation is degraded (as Bernstein (1993, p 129) notes, an expelled trader not only no longer has the right to trade on the New York bourse but "his name is circulated to all the bourses in the world federation and posted on their bulletin boards") unreliable actors in a reputation network can suffer through reduced opportunity as other parties learn of transgressions and deem the defaulting actor less appropriate as a partner.

Under these conditions, foresighted actors should be disposed to act cooperatively. We note that it doesn't matter if the motivation for trustworthy behavior is situational or intentional: the effect is the same in terms of building a reputation. Therefore, to avoid confusion about which type of trust might be meant, we will refer to consistent, cooperative behavior as "reliable". In either event, partners of such actors could rely on the institutional structure to defray governance costs since they can be confident the partner will not act opportunistically and reliable actors should be preferred partners. Put differently, if reputations for reliability and trustworthiness permit actors to discriminate among potential partners, they should rationally prefer to ally with those that will allow them to reduce their own costs of governance. In a set of actors with differing reputations, then, reliable actors should be preferred partners and therefore entertain more opportunities to ally than the less reliable.

Hypothesis 1: Reliable actors will receive more offers to ally than less reliable actors.

Aside from a greater quantity of offers, the quality of offers the actors receive should differ and reliable actors should receive offers from more reliable potential partners. Firms that have achieved a high industry or network standing are not often motivated to ally with lower rated firms because such affiliation can erode status. Thus, these firms will practice exclusivity, preferring to ally with organizations of similar status (Benjamin and Podolny 1999; Podolny 1994). Similarly, Nooteboom, et al, (1997) include among the mechanisms for controlling relational risk in alliances selecting only partners that share norms and values.

Hypothesis 2: Reliable actors will receive offers of higher quality (i.e., relatively more offers from reliable potential partners).

If reliable actors have a better choice set, they are differentially able to choose partners that are also reliable and subsequently choose to reduce their own governance costs (Benjamin and Podolny 1999; Hill 1990).

Hypothesis 3: Reliable actors will be more likely to choose and partner with other trustworthy actors.

Hypothesis 4: Reliable actors will be able to economize on own costs of governance.

Therefore, because reliable actors can choose better partners and avoid governance costs others may have to incur, we expect that they should have better performance.

Hypothesis 5: Reliable actors will have higher returns from their choices.

\section{RESEARCH DESIGN}

To study the effects of reputation on how transaction opportunities are generated and governed, we developed an experimental approach. Trustworthiness or the reputation for it is a difficult attribute to capture as reputation typically includes many components (Cravens et al. 2003) but an experiment allowed us to constrain reputation to a single indicator (a participant's history of cooperation) and control for other hidden or systemic 
influences. We designed a Web based game that gave participants the opportunity to make and accept arms-length offers for alliance with other players and to choose how to manage the transaction. Economics experiments like ours have elsewhere been used to assess cooperative behavior (Knez and Camerer 1994; Shamdasani and Sheth 1995; Weber et al. 2001) and many use MBA students as subjects (Flynn et al. 2001; Langfred 2004; Leatherwood and Conlon 1987; Priem and Rosenstein 2000). Though experiments like these may only be "simple laboratory creations", they do model how more complex processes might work in the world (Knez and Camerer 1994, p 108).

The participants in our study were 114 MBA students enrolled in strategy, human resource management and business ethics classes at an eastern U.S. university. Participation was voluntary and all who participated in at least $75 \%$ of the rounds were awarded class credit. Six players dropped out of the game, leaving 108 participants. Of these, $26 \%$ were full-time students and $74 \%$ were part-time students employed full-time in professional positions. Sixty-one percent of the participants were male, $39 \%$ female and the average age was 29 years.

The idea of our game was to generate competition for alliance partners and to assess the role that reputation had on that competition. Our approach tracked the choices players made about which partners to work with and how to manage those transactions when information about the partners was limited to a simple measure of that partner's past decisions. Overall, players competed to maximize alliance points won over the course of the game (with an incentive of a $\$ 75$ restaurant certificate) but the first objective of the game was to enter single round alliances with another player and split contracts worth 500 points in total. The way the points were allocated to each player depended on the joint strategies chosen in that transaction.

Our game was designed as a version of the Prisoner's Dilemma (PD) but, unlike an iterated game where players develop a history with each other (and a tacit judgment of reliability), players in this game had no guarantee of repeated interactions. To establish reputations, we provided information about the strategies potential partners had employed in the past. For each player, we posted a score that captured the number of times in the past five transactions the participant had played "cooperate". For example, a player that had cooperated four out the last five transactions would have a reputation score of 4 . Players could learn more about potential partners by purchasing additional history at 10 points per five prior transactions (though this option was used in less than $.9 \%$ of the offers and is excluded from our analysis). We did not show the strategies players had selected for any contracts that were not consummated. Because history about others was available to the players, PD games like this have been described as coordination games where the interest is in if players "trust others to choose the high payoff actions" (Knez and Camerer 1994, p 107).

As in any version of a Prisoner's Dilemma game, players could choose to cooperate or defect, with varying payoffs. As Hill (1990) observes, games of this sort generate high asset specificity in the choice of partners. Since there is value only in consummating a transaction and there is no recourse to other potential partners in case of defection in that round (constituting a form of temporal asset specificity (Williamson 1991)), the composite rents are completely at risk and should demand governance. In alliances, firms can protect themselves when asset specificity is high by investing in governance such as bonding or monitoring to prevent losses due to opportunistic behavior by partners but these costs dissipate the rents that should accrue to the transaction (Hill 1990). Our game proxied these governance costs by offering the opportunity for players to purchase insurance at a cost of 50 points per purchase against the chance of defection by a potential partner, so this became a four strategy version of the PD. The insurance put players in the same position that effective governance would, i.e., made whole less the costs of governance. That is, insurance blocked loss due to defection. Insured players whose partner did not defect still bore the cost of purchasing protection. In our game, the Defect/Insure and Defect/No insurance are weakly dominant versus their parallel Cooperate strategies, which suggests that utility maximizing players will strictly prefer a Defect strategy (Kreps 1990b). Between the two defect strategies, Defect/Insure is the equilibrium solution so, overall, we should expect players to converge to a Defect/Insure strategy. Table 1 shows the payoffs for each strategy combination. 
Table 1: Game Payoff Matrix

Player 1

Player 2

\begin{tabular}{|l|c|c|c|c|}
\hline & $\begin{array}{c}\text { Coop/ No } \\
\text { Insurance }\end{array}$ & $\begin{array}{c}\text { Coop/ } \\
\text { Insurance }\end{array}$ & $\begin{array}{c}\text { Defect/ No } \\
\text { Insurance }\end{array}$ & $\begin{array}{c}\text { Defect/ } \\
\text { Insurance }\end{array}$ \\
\hline Coop/ No & 250 & 200 & 500 & 450 \\
Insurance & 250 & 250 & 0 & 0 \\
\hline Coop/ & 250 & 200 & 250 & 200 \\
Insurance & 200 & 200 & 200 & 200 \\
\hline Defect/ No & 0 & 200 & 250 & 450 \\
Insurance & 500 & 250 & 250 & 0 \\
\hline Defect/ & 0 & 200 & 0 & 200 \\
Insurance & 450 & 200 & 450 & 200 \\
\hline
\end{tabular}

Participants were introduced to the game in presentations in each class as well as e-mailings with game instructions and rules which are shown in Appendix 1. Beyond publishing these rules, we did not train or advise the players on how to select strategies. In particular, we did not give any further information about insuring transactions so the players were left to their own devices to construct decision rules for when and if they would insure an alliance transaction. Players registered for the game online and selected a "game name" (drawn from noun lists for birds, trees, plants, etc, ) intended to preserve anonymity and to prevent real world reputations and side negotiations from skewing alliance decisions. As Granovetter (1985) notes, PD type choices are often obviated by personal relations outside the game. Therefore, we wanted to restrict private information as much as possible to focus the choice mechanism on our single reputation measure. To that end, each player signed a pre-game agreement agreeing that security was important and that players would not divulge their game names to other students. Post-game interviews indicate that the players did maintain anonymity. The game was developed by the authors and placed on a university server (see www/...). The design of this game is consistent with Knez and Camerer's (1994) observation that economic experiments should address purpose, context, and incentives. That is, the purpose of this game is to operationalize reputation effects in a player directed context with both a participation and outcome incentive.

\section{PROCEDURE}

Rounds in the game were played twice per week over the course of a semester with each round run in real time over a two day period. At the outset, we announced that the game would consist of 15 to 24 rounds, the actual number only announced at the outset of the last (twentieth) round. At the beginning of each round, $70 \%$ of the players (Contractors) were randomly selected based on a uniform distribution to own contracts or the right to choose an alliance Partner. This was intended to assure that not all players would score in each round. The complete list of Contractors was published on the game website. All players, Contractors or not, could sign in to the game and make offers (that is, offer to be a partner) to up to four Contractors. Contractors could not make offers to themselves. When each player made an offer to ally, he or she had to choose a strategy at that time. That strategy, to cooperate or defect, with or without insurance, was hidden from the Contractor until after an alliance offer was accepted. This, in effect, turned sequential decisions into simultaneous ones.

Later in the round, Contractors would sign on again, choose a Partner from the list of offers, and select a strategy for the transaction with no idea what strategy the Partner was playing. There was no limit to the number of offers a Contractor could receive but if there were none, the Contractor could not score in that round. Once an offer was accepted, the Contractor could accept no more offers nor could the Partner be selected as a partner by another Contractor in that round. The results for each consummated transaction were available to the Contractor and Partner immediately and after each round, we published an ordered list of players and their total scores on the website so all participants knew their relative position. 


\section{MEASURES}

\section{Dependent Variables}

We tested hypotheses for five dependent variables. The first dependent variable was the sum of offers (total offers) made to a Contractor in a given round. The second was a measure of the general reputation score of the potential Partners, which we constructed as the mean of reputation scores (mean partner reputation) for all the offers a Contractor received in a particular round. The third variable was a dichotomous assessment of if Contractors chose partners of the same strategic type (strategy match) in a given round. The fourth dependent variable measured the extent to which players economized on governance costs by dichotomously assessing if insurance was purchased (insurance). Our fifth dependent variable was a continuous measure of how a specific Contractor score varied from the average Contractor score for that round (contractor score). Our data consisted of 7,442 offers to Contractors in 1,445 contracts and of these, 1041 resulted in consummated alliances. We excluded data from the first two rounds as reputations were just being developed. With respect to the last three dependent variables, we also excluded the results of the decision from the last round to exclude backward induction problems (Hill 1990; Kreps 1990b).

\section{Independent Variable}

Because we were able to successfully insist on player anonymity and because the names were not indicative of personal characteristics or hints to the player's real identity, we are able to work with a single independent variable: reputation score. To account for the substantial number of choices made in the early rounds when players had not yet accumulated five transactions, we coded the reputation scores into four categories. Players that in their published history had always cooperated were coded AC. Players who cooperated half the time or more (but not always) were coded UC (usually cooperated). Players who had played pure defect strategies were coded always defected (AD) and players who usually defected (defected in more than half of the prior five transactions but not always) were coded UD. This allowed us to structure the reputation score as a categorical variable.

Hypotheses 3, 4, and 5 address choice or the result of choice for Contractors so for these we include control variables addressing player sex, age, and full-time versus part-time status. We employed several techniques to analyze our data. Our first, second, and fifth dependent variables are continuous, we chose an OLS approach for those DVs. The strategy match and insurance variable are dichotomous and evaluated in logit regressions.

\section{RESULTS}

Descriptive statistics for the strategies, offers, and alliances per round are shown in Table 2. The results of the regressions are shown in Table 3. All regressions were run with the Always Cooperate strategy as the omitted category so the results are expressed relative to that strategy and all models are significant at $\mathrm{p}>.01$. With respect to the total number of offers each strategy attracted, the analysis shows that the coefficients for the three other strategies are negatively signed and significant at the $\mathrm{p}<.01$ level. Relative to the AC strategy, any other strategy appears to result in fewer offers, supporting $\mathrm{H} 1$. With respect to the quality of the offers, the results indicate that the three other strategies generate offers from less reliable potential partners. Again, all coefficients are negatively signed and significant at the $\mathrm{p}<.01$ level, supporting $\mathrm{H} 2$. The logit regression for $\mathrm{H} 3$ indicates that players other than AC players were much less likely to choose partners of an equivalent strategic type, supporting the hypothesis with coefficients negative significant at $\mathrm{p}<.01$. The results for $\mathrm{H} 4$ indicate that relative to other strategies, players using the AC strategy are less likely to purchase insurance, thereby reducing their governance costs. The coefficients are positive and significant at the $\mathrm{p}<.01$ level. We also note that this is the only decision where a control variable is significant: part-time students were less likely to purchase insurance. Finally, the analysis of contractor score for H5 indicates that relative to AC players, contractor scores for other strategies were lower. Coefficients were negatively signed and significant at $\mathrm{p}<.01$. 
Table 2: Descriptive Statistics

\begin{tabular}{|l|c|c|}
\hline & Mean & St. Dev \\
\hline AD/round & 16.7 & 5.3 \\
\hline UD/round & 32.4 & 10.5 \\
\hline UC/round & 35.8 & 10.2 \\
\hline AC/round & 20.8 & 5.5 \\
\hline Offers/round & 369.9 & 35.2 \\
\hline Alliances/round & 57.9 & 10.3 \\
\hline Mean reputation/round & 1.5 & 0.2 \\
\hline Insurance/round & 31.4 & 6.3 \\
\hline Contractor score/round & 209.1 & 11.7 \\
\hline
\end{tabular}

Table 3: Regression Results Relative To Strategy AC (Always Cooperate)

\begin{tabular}{|c|c|c|c|c|c|}
\hline & H1 & H2 & H3 & H4 & H5 \\
\hline DV & Total offers & Mean reputation & Strategy match & Insurance & Contractor score \\
\hline \multicolumn{6}{|l|}{ Strategy } \\
\hline Always Defect & $\begin{array}{c}-6.58 \\
(0.44)^{* *}\end{array}$ & $\begin{array}{c}-0.73 \\
(0.06)^{* *}\end{array}$ & $\begin{array}{c}-2.26 \\
(0.25)^{* *}\end{array}$ & $\begin{array}{c}1.13 \\
(0.21)^{* *}\end{array}$ & $\begin{array}{c}-0.23 \\
(0.05)^{* *}\end{array}$ \\
\hline Usually Defect & $\begin{array}{c}-7.63 \\
(0.37)^{* *}\end{array}$ & $\begin{array}{c}-0.70 \\
(0.05)^{* *}\end{array}$ & $\begin{array}{c}-1.24 \\
(0.19)^{* *}\end{array}$ & $\begin{array}{c}1.15 \\
(0.18)^{* *}\end{array}$ & $\begin{array}{c}-0.21 \\
(0.04)^{* *}\end{array}$ \\
\hline $\begin{array}{l}\text { Usually } \\
\text { Cooperate }\end{array}$ & $\begin{array}{c}-6.11 \\
(0.36) * *\end{array}$ & $\begin{array}{c}-0.48 \\
(0.05)^{* *}\end{array}$ & $\begin{array}{c}-1.15 \\
(0.18)^{* *}\end{array}$ & $\begin{array}{c}0.76 \\
(0.17)^{* *}\end{array}$ & $\begin{array}{c}-0.11 \\
(0.04)^{*}\end{array}$ \\
\hline $\operatorname{Sex}(F=1)$ & & & $\begin{array}{c}0.08 \\
(0.14)\end{array}$ & $\begin{array}{l}-0.14 \\
(0.13)\end{array}$ & $\begin{array}{c}0.01 \\
(0.04)\end{array}$ \\
\hline Age & & & $\begin{array}{c}0.01 \\
(0.01) \\
\end{array}$ & $\begin{array}{c}0.01 \\
(0.01) \\
\end{array}$ & $\begin{array}{c}0.00 \\
(0.00) \\
\end{array}$ \\
\hline Status $(\mathrm{FT}=1)$ & & & $\begin{array}{c}0.18 \\
(0.17)\end{array}$ & $\begin{array}{c}-0.33 \\
(0.16)^{*}\end{array}$ & $\begin{array}{l}-0.17 \\
(0.04)\end{array}$ \\
\hline Constant & $\begin{array}{l}10.24 \\
(0.29)\end{array}$ & $\begin{array}{c}1.83 \\
(0.04)\end{array}$ & $\begin{array}{c}0.35 \\
(0.34)\end{array}$ & $\begin{array}{l}-0.98 \\
(0.34)\end{array}$ & $\begin{array}{c}1.11 \\
(0.08)\end{array}$ \\
\hline $\mathbf{N}$ & 1435 & 1435 & 1037 & 1037 & 1037 \\
\hline F $(3,1431)$ & 153.19 & 72.93 & & & 5.79 \\
\hline Prob $>F$ & 0.0000 & 0.0000 & & & 0.0000 \\
\hline $\mathbf{L R} \square^{\square}$ & & & 111.72 & 48.79 & \\
\hline Prob> $>\square^{\square}$ & & & 0.0000 & 0.0000 & \\
\hline R-squared & 0.24 & 0.13 & & & 0.03 \\
\hline Adj R-squared & 0.24 & 0.13 & & & 0.03 \\
\hline Pseudo-R^2 & & & 0.08 & 0.03 & \\
\hline
\end{tabular}

$\begin{array}{ll}\dagger & \mathrm{p}<.10 \\ * & \mathrm{p}<.05 \\ * * & \mathrm{p}<.01\end{array}$

\section{DISCUSSION AND CONCLUSIONS}

The purpose of this paper was to deconstruct the process by which actors with good reputations may derive benefit from that reputation in alliance transactions. We proposed that reliable actors get more and better opportunities to ally which permits them to select better partners and reduce own governance costs. This should result in better performance vis a vis other less reliable actors. Using data derived from experiment based transactions, we find that our hypotheses are broadly supported and offer the following observations.

Our first results show that trustworthy players do receive more offers but the coefficients indicate the effect is not completely linear. Further analysis shows that players using a Usually Defect strategy were significantly less likely 
to receive offers than any other strategy. It appears that being unreliable is less attractive than being completely (but reliably) untrustworthy. This is somewhat counterintuitive and has managerial implications. If reputation is an asset that is constructed over time and through interactions, the uncertainty that attends unreliable behavior could suggest a barrier to firms that would like to improve their own reputations. A lack of opportunities would make it more difficult to enter alliances even if the firm intends to cooperate, which supports Barney and Hansen's (1994) position that it should be difficult and time consuming for firms to change the perception of their trustworthiness.

The analysis also supported Hypothesis 2 in that players using an AC strategy received significantly better offers measured as the mean reputation score for all offers received by players of a given strategy in a particular round. Further analysis indicates that this is a conservative result: Figure 1 shows that the difference in mean reputation scores, especially between $\mathrm{AC}$ and $\mathrm{AD}$ strategies, becomes more pronounced over time. We interpret this to reflect the way players developed and applied decision rules about potential partners. One obvious rule appears to be that AC players would offer to and accept from only other AC players. A less obvious rule for AD players emerged: even though $\mathrm{AC}$ partners are preferable, the application of the $\mathrm{AC}$ rule means that offers from $\mathrm{AD}$ players would rarely be accepted so that an offer to an AC player was a wasted offer.

Figure 1: Mean Reputation Scores For Received Offers By Strategy By Round

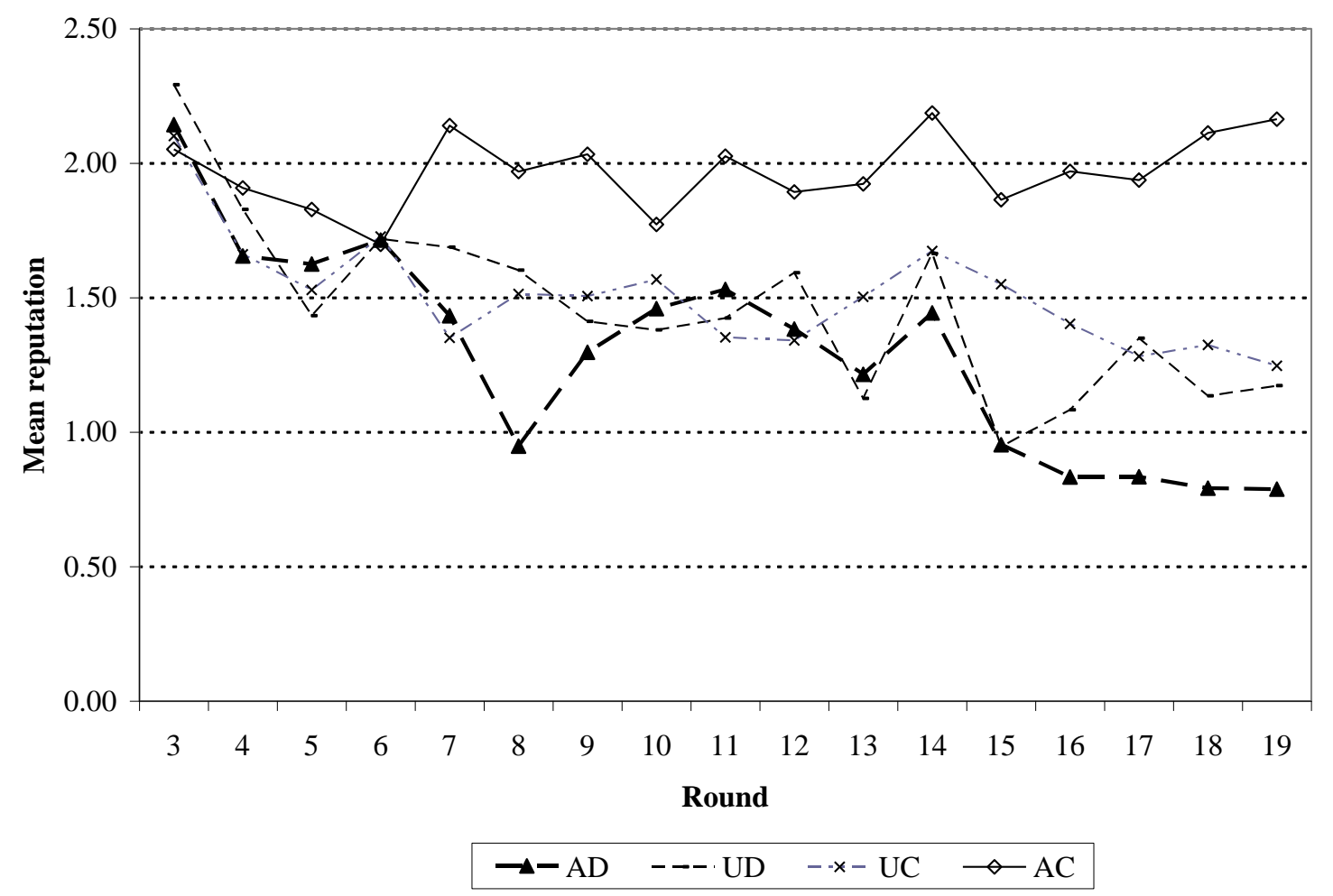

Over time, several exchange subgroups emerged. As hypothesized in $\mathrm{H} 3$, AC players strongly preferred to choose AC partners and did not often "choose down". This was true of UC players as well, though the effect is not as strong. UC player would prefer AC partners and sometimes had that opportunity, but the strength of the AC clustering means this was not commonly available. At lower reputation levels, the grouping weakens as players would strongly prefer to choose up so they become opportunists, choosing the best available. As a complement to this analysis, we also assessed (but do not show here) the differences between players who consummated alliances and those that did not. On mean, players who neglected to consummate alliances had lower reputation scores than those who did, significant at $\mathrm{p}<.01$. Collectively, that $\mathrm{AD}$ type players are forced into lower value exchanges and, ultimately, are 
more likely to drop out of the exchange process illustrate Hill's (1991) claim: in the long run, firms that are habitually opportunistic should be driven from the market. While our study was brief and the game rules provided motivation for continued participation, the actual behavior of players facing poorer opportunities and probable lower results reflects Hill's conjecture.

Hypotheses 4 and 5 address the governance decisions and the ultimate effects of player choices. The results support the hypotheses but we note that the models are not highly explanatory. Our interpretation is that this is because outcomes reflect a sequence of related choices. To the extent that actors may not make optimal partner choices, then the subsequent effects including better performance will not be realized. Our results also reflect the fact that some actors are myopic.

Our approach used the interactions of MBA students to model transaction decisions and clearly, a limitation to our paper is that individuals are not firms. However, alliances are not developed between firms per se but rather between individuals in those firms. Reputations develop between organizations as a result of repeated interactions and friendship between individuals in those firms (Nooteboom et al. 1997; Olk and Elvira 2001; Ring and Van de Ven 1992). Thus, we argue, the judgments of managers like those we used in our experiment are often the foundation of interfirm transactions and can provide a guide to behavior at the firm level. To this end, we were encouraged to observe that in the only case where a control variable for the choice hypotheses signified, we find that part time students (i.e., those already working) were less likely to purchase insurance for their transactions, suggesting a deeper appreciation of the implications of reputation.

Another limitation to interpreting the results of our study is the clarity of our reputation signal. Our reputation measure is unidimensional and objectively accurate but in the world, firm reputation is multidimensional, subjective, and noisy (Deephouse and Carter 2005; Dollinger et al. 1997; Lewellyn 2002). To the extent that reputation is a belief by others about the true nature of a person or firm, the data that are used to construct that belief can be more or less accurate. For example, at the most innocuous level, a manager might have an honest disagreement about the performance of a partner, which dissatisfaction may be wrongly interpreted by others. Information might also be manipulated for strategic reasons, specifically, to mislead others about the reputation of a third (Williamson 1975). In any event, if information like this is costly to develop, managers may under invest and leave themselves exposed to error.

However, exchanges like these are not often conducted in an informational vacuum. When firms or employees belong to organizations such as an industry, trade organization, technological field or R\&D venture, they are part of a more or less structured network. Informational resources develop through direct and indirect interactions that allow them to cost effectively profile or characterize other firms in the network with respect to attributes such as competences or reliability (Gulati 1999; Gulati and Gargiulo 1999). The most accurate history comes from direct (relational) interactions with firms in the network (Gulati 1995a, 1995b; Podolny 1994) but indirect experience or referrals from trusted partners can expand the stock of reliable information (Gulati 1995b; Stuart 1998).

Firms on the periphery or outside a network may not have the richness of relations that more central firms do, but even then, the structure of the network and positions of firms in that network can provide useful cues about reliability (Gulati 1998). Because central or high profile firms in a network have more ties with other firms and because these firms would prefer to partner with firms of equal or near equal status, affiliates can benefit from shared reputation (Benjamin and Podolny 1999; Stuart 1998), presenting a richer choice set for firms outside. This and the way our results illustrate Podolny's (1994) notion of exchange exclusivity suggests that the problem for peripheral firms is not identifying good potential partners but developing legitimacy as a partner themselves.

Finally, even though reputation is multidimensional, Dollinger et al, (1997) show that managers are able to distinguish between reputation elements and not make wholesale attributions even when one aspect of reputation is damaged. To the extent that managers can reach a judgment about a potential partner's reliability, then, the general complexity of reputation shouldn't diminish these results. 
Our study used an experimental approach to assess how reputations for reliability in transactions affected the opportunities players enjoyed and the decisions they made. In general, our results show that developing a reputation for reliability pays off in that such players receive more and better offers and are subsequently able to leverage these opportunities into better performance. The basis for choice was not trust in the richest intentional sense but simpler reliance on economic self-interest. These results illustrate Williamson's (1993a) claim that reputation effects can be included in the efficient exchange. To the extent that the participants are also managers, these results could be reflected in the real world in preferences for and decisions about alliance partners.

\section{APPENDIX}

\section{The Alliance Game - How To Play}

The objective of the Alliance Game is to score the most points by entering into and managing alliances. There are two ways you can enter an alliance: you can accept an offer to ally with someone else or have an offer accepted by another player. Alliances involve contracts or opportunities to work together. In each round, most (but not all) players will own the rights to a contract and can accept offers from other players. In order to score points, the contract holder must accept an offer from one player among those who make offers. Also, in each round, all players will have the chance to see who has contracts available and make offers to them. You score points as here only if your offer is accepted.

1. A contract is worth 500 points in total.

2. In each round, every player can examine who the contract-holders are and make offers to up to four of them (so choose wisely). You can have only one offer accepted, though, and as soon as one of your offers is accepted, the offers to other players are eliminated.

3. In each round, most (but not all) of the players will be contract holders. Contract holders can examine any number of offers from other players and accept one to execute a contract. Once an offer is accepted, the alliance is complete.

4. In each offer or acceptance, players must decide before accepting or making an offer how to manage the alliance. There are two positions a player can take:

a. Cooperate in the contract. In this case, the player agrees to split the contract with the partner.

b. Defect from the contract. In this case, the player is claiming the entire contract value.

c. Examples:

i. $\quad$ If $\mathrm{A}$ and $\mathrm{B}$ both decide to cooperate, they each receive 250 points

ii. If $\mathrm{A}$ cooperates and $\mathrm{B}$ defects, A receives 0 points and $\mathrm{B}$ receives 500 points.

iii. If $A$ and $B$ both decide to defect, they each receive 250 points (because they claim the partner's share but lose their own).

5. Insurance: Players can insure against loss if a partner defects by purchasing insurance at a cost of 50 points. This makes the player whole for that round, less the cost of insurance. In example ii above, if A had bought insurance, A would have received 200 points for the round $(250-50=200)$.

6. Information: players will be provided recent history about the transactions potential partners have had. Every player with a contract or making an offer will have the cooperation decisions from the last five transactions shown. Players can purchase more history (in five transaction increments) for 10 points per purchase. Each purchase is history about one player only. 


\section{REFERENCES}

1. Barney, J. B. and M. H. Hansen. 1994. Trustworthiness as a source of competitive advantage. Strategic Management Journal, 15: 175.

2. Benjamin, B. A. and J. M. Podolny. 1999. Status, quality, and social order in the California wine industry. Administrative Science Quarterly, 44: 563-589.

3. Bernstein, L. 1992. Opting out of the legal system: Extralegal contractual relations in the diamond industry. Journal of Legal Studies, 21(1): 115-157.

4. Casciaro, T. 2003. Determinants of governance structure in alliances: the role of strategic, task and partner uncertainties. Industrial and Corporate Change, 12(6): 1223-1252.

5. Cravens, K., E. G. Oliver, and S. Ramamoorti. 2003. The reputation index: Measuring and managing corporate reputation. European Management Journal., 21(2): 200.

6. de Castro, G. M., J. E. N. López, and P. L. Sáez. 2006. Business and social reputation: Exploring the concept and main dimensions of corporate reputation. Journal of Business Ethics, 63(4): 361-370.

7. Deephouse, D. L. 2000. Media reputation as a strategic resource: An integration of mass communication and resource-based theories. Journal of Management, 26(6): 1091-1112.

8. Deephouse, D. L. and S. M. Carter. 2005. An examination of differences between organizational legitimacy and organizational reputation. Journal of Management Studies, 42(2): 329-359.

9. Dollinger, M. J., P. A. Golden, and T. Saxton. 1997. The effect of reputation on the decision to joint venture. Strategic Management Journal, 18(2): 127.

10. Flynn, F. J., J. Chatman, and S. E. Spataro. 2001. Getting to know you: The influence of personality on impressions and performance of demographically different people in organizations. Administrative Science Quarterly, 46: 414-442.

11. Ghoshal, S. and P. Moran. 1996. Bad for practice: A critique of the transaction cost theory. Academy of Management Journal, 21(1): 13-47.

12. Gulati, R. 1995 a. Does familiarity breed trust? The implications of repeated ties for contractual choice in alliances. Academy of Management Journal, 38(1): 85-112.

13. Gulati, R. 1995 b. Social structure and alliance formation patterns: A longitudinal analysis. Administrative Science Quarterly, 40(4): 619-652.

14. Gulati, R. 1998. Alliances and networks. Strategic Management Journal, 19(4): 293-317.

15. Gulati, R. 1999. Network location and learning: The influence of network resources and firm capabilities on alliance formation. Strategic Management Journal, 20(5): 397.

16. Gulati, R. and M. Gargiulo. 1999. Where do interorganizational networks come from? American Journal of Sociology, 104(5): 1439-1493.

17. Gulati, R. and H. Singh. 1998. The architecture of cooperation: Managing coordination costs and appropriation concerns in strategic alliances. Administrative Science Quarterly, 43(4): 781-814.

18. Hill, C. W. L. 1990. Cooperation, opportunism, and the invisible hand: Implications for transaction cost theory. Academy of Management Review, 15(3): 500-513.

19. Knez, M. and C. Camerer. 1994. Creating expectational assets in the laboratory: Coordination in "weakestlink" games. Strategic Management Journal, 15: 101-119.

20. Kreps, D. M. 1990a. Corporate culture and economic theory. In Alt, J. E., and K. A. Shepsle (Eds.), Perspectives on Political Economy: 90-143. Cambridge: Cambridge University Press.

21. Kreps, D. M. 1990b. A Course in Microeconomic Theory. Princeton, NJ: Princeton University Press.

22. Langfred, C. W. 2004. Too much of a good thing? Negative effects of high trust and individual autonomy in self-managing teams. Academy of Management Journal, 47(3): 385-399.

23. Leatherwood, M. L. and E. J. Conlon. 1987. Diffusability of blame: Effects of persistence in a project. Academy of Management Journal, 30(4): 836-847.

24. Lewellyn, P. G. 2002. Corporate reputation: Focusing the zeitgeist. Bus. Soc., 41(4): 446.

25. McCabe, K. A., M. L. Rigdon, and V. L. Smith. 2003. Positive reciprocity and intentions in trust games. $J$. Econ. Behavior and Org., 52(2): 267-275.

26. Nooteboom, B., H. Berger, and N. G. Noorderhaven. 1997. Effects of trust and governance on relational risk. Academy of Management Journal, 40(2): 308-338. 
27. Olk, P. and M. Elvira. 2001. Friends and strategic agents: The role of friendship and discretion in negotiating strategic alliances. Group and Org. Mgmt., 26(2): 124-164.

28. Parkhe, A. 1993. Strategic alliance structuring: A game theoretic and transaction cost examination of interfirm cooperation. Academy of Management Journal, 36(4): 794-820.

29. Podolny, J. M. 1994. Market uncertainty and the social character of economic exchange. Administrative Science Quarterly, 39: 458-483.

30. Priem, R. L. and J. Rosenstein. 2000. Is organization theory obvious to practitioners? A test of one established theory. Organization Science, 11(5): 509-524.

31. Reuer, J. J. and A. Arino. 2002. Contractual renegotiations in strategic alliances. J. Mgmt., 28(1): 47-68.

32. Ring, P. S. and A. H. Van de Ven. 1992. Structuring cooperative relationships between organizations. Strategic Management Journal, 13(7): 483-498.

33. Ring, P. S. and A. H. Van de Ven. 1994. Developmental processes of cooperative interorganizational relationships. Academy of Management Review., 19(1): 90-117.

34. Shamdasani, P. N. and J. N. Sheth. 1995. An experimental approach to investigating satisfaction and continuity in marketing alliances. Eur. J. Mktg., 29(4): 6-23.

35. Stuart, T., E. 1998. Network positions and propensities to collaborate: An investigation of strategic alliance formation in a high-technology industry. Administrative Science Quarterly, 43(3): 668-698.

36. Weber, R., C. Camerer, Y. Rottenstreich, and M. Knez. 2001. The illusion of leadership: Misattribution of cause in coordination games. Organization Science, 12(5): 528-598.

37. Weigelt, K. and C. Camerer. 1988. Reputation and corporate strategy: A review of recent theory and applications. Strategic Management Journal, 9(5): 443-454.

38. Williamson, O. E. 1975. Markets and Hierarchies. New York, London: Free Press.

39. Williamson, O. E. 1991. Comparative economic organization: The analysis of discrete structural alternatives. Administrative Science Quarterly, 36(2): 269.

40. Williamson, O. E. 1993a. Calculativeness, trust, and economic organization. Journal Of Law and Economics., 36(1): 453-486.

41. Williamson, O. E. 1993b. Opportunism and its critics. Managerial and Decision Economics. 14(2): 97.

42. Williamson, O. E. 1999. Strategy research: Governance and competence perspectives. Strategic Management Journal, 20(12): 1087-1108.

43. Williamson, O. E. 2002. The theory of the firm as governance structure: From choice to contract. Journal of Economic Perspectives, 16(3): 171-195. 
International Business \& Economics Research Journal - June 2007

Volume 6, Number 6

NOTES 